\title{
The national and international implications of a decade of doctor migration in the Irish
}

context

Posy Bidwell ${ }^{1}$, Niamh Humphries ${ }^{2}$, Patrick Dicker ${ }^{2}$, Steve Thomas ${ }^{1}$, Charles Normand ${ }^{1}$, Ruairí Brugha $^{2}$

${ }^{1}$ Health Policy \& Management, Trinity College Dublin, Ireland

2 Department of Epidemiology and Public Health Medicine, Royal College of Surgeons in Ireland, Dublin

\begin{abstract}
Background

Between 2000 and 2010, Ireland became increasingly dependent on foreign-trained doctors to staff its health system. An inability to train and retain sufficient doctors to meet demand is the primary reason for the dependence on foreign-trained doctors. By 2008 the proportion of foreign-trained doctors was the second highest in the OECD. This increased dependence on international medical migration has both national and international policy implications.
\end{abstract}

\section{Methods:}

Registration data were obtained from the Medical Council of Ireland ( $\mathrm{MCl}$ ) for a ten year period: 2000-2010. Data indicate country of qualification but not nationality. The total number of registrants and entrants ( $n$ ) was determined for each year. Immigration data were also obtained on the number of work visas issued to doctors. Registration and visa data were then compared in order to estimate doctor migration to Ireland 2000-2010.

\section{Results:}

The proportion of foreign-trained doctors rose from $13.4 \%$ of all registered doctors in 2000 to $33.4 \%$ by 2010 . The largest increase was in foreign-trained doctors from outside the EU, rising from $972(7.4 \%)$ in 2000 to 4,740 (25.3\%) of registered doctors in 2010. The biggest source country in 2000 was Pakistan. By 2010, South Africa had become the biggest source country. The number of foreign-trained doctors from other EU countries doubled from 780 in 2000 to 1,521 in 2010.

\section{Conclusions}

Registration data are likely to over-estimate and visa data under-estimate the numbers of doctors actively working in Ireland. However, they serve to illustrate Ireland's rapidly increasing and potentially unsustainable reliance on foreign-trained doctors; and to highlight the need for better data to measure migratory flows. Improved measurement of health worker migration is necessary both for national workforce planning and to fulfil the requirements of the WHO Global Code on the International Recruitment of Health Personnel. 
International doctor migration has been a feature of the global health agenda since the late 1990s [1]. Doctor migration is not a new phenomenon; issues around international doctor migration were documented in Mejia's 1978 benchmark paper, which highlighted the detrimental effects of increased health worker migration on resource poor nations, the lack of reliable migration data and the implications for workforce planning [2]. These issues still affect health systems today [3] and further concerns relate to the worldwide shortage of health personnel, currently estimated at more than 4.3 million [4].

Shortages of doctors are experienced by both developed and developing countries. The European Commission forecasts that 'the EU will face a shortage of 1 million health professionals by 2020 if existing workforce problems are not addressed' (European Commission cited in [5]). Developed countries have addressed, at least in part, their shortages by recruiting doctors from developing countries and it is argued that demand for labour is the driving force behind medical migration [6].

Many OECD countries have seen rapid increases in the proportion of foreign-trained doctors working within their health systems indicating an increasing dependence on international medical migration [4] rather than a decreasing dependence advocated by the Global Code on the International Recruitment of Health Personnel [7]. By 2008, foreign-trained doctors made up 39\% of the workforce in New Zealand, with other countries also highly dependent on foreigntrained doctors - Australia (23\%), USA (26\%), and the UK (32\%). Figure 1 shows the proportion of foreign-trained doctors in selected OECD countries from 2000 to 2008 . Ireland in particular saw dramatic increases in the proportion of registered foreign-trained doctors, rising from just over $11 \%$ of the overall medical register to $36 \%$ by 2008 , making it the second highest in the OECD [4]. What makes Ireland distinct from other destination countries is the rapid rate of increase, whereby the proportion of foreign-trained doctors registered to practice tripled from 2001 to 2008. 
Figure 1: Proportion of foreign-trained doctors in selected OECD countries 2000-2008

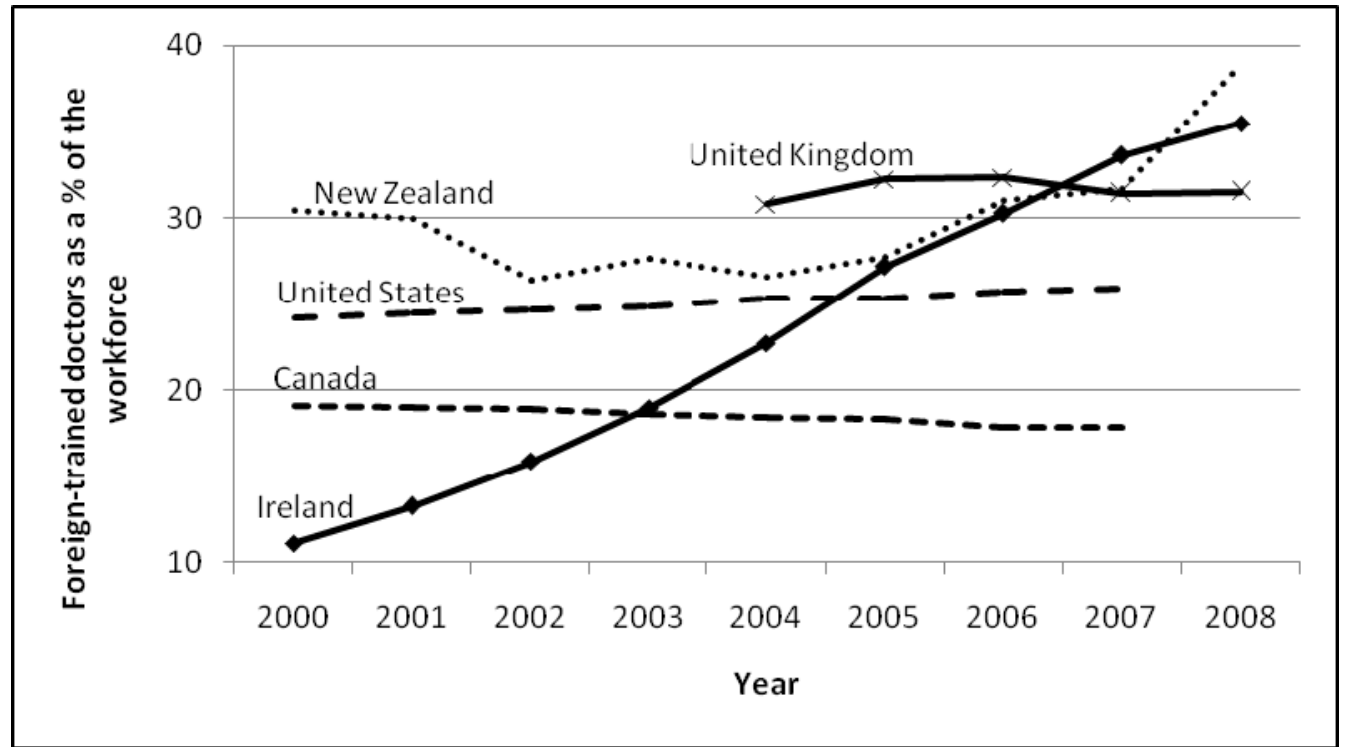

Source: $\underline{w w w . o e c d . o r g / h e a l t h / w o r k f o r c e ~}$ Incomplete data for Canada, the United States and the UK

Doctor migration is a significant issue for policy makers at a national and international level. For effective workforce planning policy makers need to know the total number of health workers available within the system (the 'stock') and the 'flows', both into and out of the health system [1]. In relation to doctors, inflows include new graduates of national medical schools and qualified doctors arriving from other countries. Outflows, which reduce the available stock of practicing doctors, are due to doctors emigrating, retiring, dying or leaving the health services for other reasons [1]. In Ireland the ability to accurately assess the true extent of doctor migration - both immigration and emigration - remains a significant policy challenge [8-10]. National policy makers need better evidence about migration to develop workforce policies [11] and the first way to address this is improved data on migratory flows [1].

At an international level the consequences of medical migration are well documented $[3,6,12$, 13] and The Global Code has placed doctor migration firmly on the policy agenda by highlighting the ethical implications of health worker migration, particularly when it undermines the health systems of source countries [7]. Additionally, the first report to the World Health Assembly on health personnel migration is due in 2012 and destination countries, such as Ireland who are major importers of foreign-trained doctors and nurses, will be required to provide data on this. 


\section{The Irish Context}

It was reported in 2005 that Ireland had the second lowest ratio of doctors per thousand population in the European Union [14]. For Ireland to meet the average of 3.26 doctors per thousand, it was estimated that there would need to be a $41 \%$ increase $(n=3754)$ in the number of doctors employed [14]. The European Working Time Directive, which restricts the number of hours doctors are allowed to work, first came into force 1 August 2004 and it was estimated that 2,500 additional junior doctors (in Ireland termed 'non-consultant hospital doctors', or NCHDs) would be required in order to fulfil the requirements of the directive [15].

By 2009 national documents were reporting shortages ${ }^{1}$ particularly amongst NCHDs and General Practitioners (GPs) [16]. Ireland has been unable to achieve full compliance the European Time Working Directive and one of the reasons cited for this is failure to fill NCHD posts [17]. Vacancy rates for NCHDs reached critical levels in February 2011 [18]. Shortages were not restricted to the hospital sector - it was estimated Ireland would also face a shortfall of 1,800 GPs by 2021 in order to meet the EU average [19]. Forecasters have also highlighted that ageing and feminisation of the workforce ${ }^{2}$ will affect the number of available doctors [19].

Supply and demand analysis [14] conducted in 2006 found that although Ireland trained sufficient medical students to meet the needs of the Irish health system, over $60 \%$ of the annual intake to medical schools were non-EU nationals [20]. Unlike Australia, which also trains large numbers of non-nationals, but retains them for work in Australia upon graduation [21], most Irish trained non-EU doctors leave Ireland on graduation [20]. Irish medical colleges are heavily dependent on the fees from non-EU students [22], but following the 2006 report, a national policy was adopted and implemented in order to expand the number of Irish (and other EU) medical student places. This was done through both undergraduate and graduate entry medical school programs and increased the Irish/EU student intake from 305 in 2006 [23] to an anticipated 725 by 2013 [24]. It was anticipated that this would guarantee an adequate supply of medical graduates to meet the demands of the Irish healthcare system [20].

\footnotetext{
${ }^{1}$ Shortages were defined as the 'situation whereby the supply of skills or labour from within the Irish labour force is insufficient to meet demand' [16]

${ }^{2}$ Women are more likely to undertake part time positions, thereby reducing the number of Full Time Equivalent (FTE) staff.
} 
This increase in the number of Irish/EU medical graduates should create a significant inflow of doctors into the health system. Ireland, however, fails to retain many Irish-trained doctors [9] to the extent that it is the European country with the highest percentage of nationally trained doctors practicing abroad [25]. This trend shows no sign of abating, with a recent survey reporting that $80 \%$ of NCHDs are considering emigration [26]. Key factors affecting doctors' decisions to leave Ireland centre around the lack of structured career paths and lack of training [10]. Furthermore, the limited number of consultant posts means that in some specialities there are only consultant posts available for less than $40 \%$ of NCHDs who have completed their training [27].

To fully understand medical migration, it is important to distinguish between active and passive recruitment. Active recruitment targets health professionals, usually through active international recruitment campaigns that 'entice' them to come to a country when they may previously have not intended to relocate; passive recruitment is where an individual initiates the decision to migrate [28]. Prior to 2011, Ireland conducted some active recruitment of doctors, but this was confined to anaesthetists [29] and locum GPs [30]. Other than this, doctor migration to Ireland was for the most part through passive recruitment. The growth in the Irish economy during the Celtic Tiger period, 1997-2007, created the need for skilled labour and migration policies (outlined in Table 1) were developed to attract skilled migrants, especially nurses and doctors. The favourable economic climate together with the expectation that doctors would be able to access training to further their careers [10] made Ireland an attractive destination. Furthermore, it was possible to initiate registration at the Medical Council of Ireland ( $\mathrm{MCl})$ at centres in Oman, India, Pakistan and Egypt [31] thereby facilitating this process.

\section{Table 1: $\quad$ Migration Policy in Ireland (2000-2010) in relation to health workers}

\begin{tabular}{|l|l|}
\hline 2000 & $\begin{array}{l}\text { Work visas were issued for } 2 \text { years on presentation of contract from an Irish employer. } \\
\text { Holders could change employers without reapplying for a visa [36]. }\end{array}$ \\
\hline 2003 & $\begin{array}{l}\text { April: End of 'employer-led' work permits [14]. } \\
\text { introduced } 2000 \text { to facilitate the active recruitment of nurses from non-EU countries [15]. }\end{array}$ \\
\hline 2004 & \begin{tabular}{l} 
February: The WA/WV scheme was modified to entitle spouses to work [15]. \\
\hline
\end{tabular} \\
\hline
\end{tabular}




\begin{tabular}{|l|l|}
\hline 2006 & December: WA/WV scheme discontinued [14]. \\
\hline 2007 & $\begin{array}{l}\text { February: Green Card scheme to facilitate the entry of non-EU skilled workers, including } \\
\text { doctors. Green cards were issued to an employee for two years [14]. }\end{array}$ \\
\hline 2010 & $\begin{array}{l}\text { June: Revised conditions for non-EU doctors working within the Irish public health system. } \\
\text { Non-EU doctors registered on the trainee specialist division of the IMC register, or those } \\
\text { working as Senior House Officers or Registrars do not require an employment permit [37]. }\end{array}$ \\
\hline
\end{tabular}

According to OECD data, by 2008 the number of doctors in Ireland rose by nearly $50 \%$ to $3.2 \%$ per 1,000 population and this increase was largely attributed to increased numbers of foreigntrained doctors [32]. However, in 2008 the economic downturn heavily affected the functioning of the health care system and spending restrictions resulted in salary reductions, loss of training grants [27] and non-payment of overtime. This together with a recruitment moratorium [10] served to make Ireland a less attractive destination for foreign-trained doctors. Doctor shortages continued into 2009 [16] and by 2011 it was reported that Ireland had been trying to address ongoing vacancy rates for NCHDs for 2 years [33]. Ireland's need for foreign-trained doctors had not decreased, but the continued shortages suggest that desire to come to Ireland had decreased. In order to rectify the critical shortage of NCHDs, in July 2011 Ireland conducted an active international campaign in India and Pakistan in order to attract doctors and fill 450 posts [18].

While it has not been possible to quantify the numbers of doctors emigrating out of Ireland, Ireland is clearly experiencing both facets of the international migration of doctors - the emigration of Irish trained doctors $[9,25]$ and immigration of foreign-trained doctors to replace them [10, 32]. This combination of factors - increased domestic demand, a delay in meeting that demand through the scale up of domestic medical education capacity and ongoing emigration of Irish trained doctors - means that Ireland has become more heavily reliant on foreign-trained doctors in recent years. Workforce planning strategies now recognise that they still need to take into account migratory flows [34]; however, Ireland does not currently have accurate data on the mobility of doctors [10].

In addition to the lack of migratory data, there is currently no comprehensive information about where foreign-trained doctors are employed within the Irish healthcare system. An estimated $55 \%$ of the 4,639 public sector NCHDs are foreign-trained [35], as are $6 \%$ of Ireland's 2,245 
consultants and 5\% of Ireland's 2,500 GPs [34]. A 2007 audit of 1305 Senior House Officers (SHO) and 671 Registrars found that at the SHO grade foreign-trained doctors occupied over half of the posts in anaesthetics, emergency medicine and surgery; and they accounted for half of the Registrars in most specialities [36]. The audit also found that $37 \%$ of Registrar posts were not currently approved for training by the relevant training body [36]. Although NCHDs are technically doctors in training, an estimated 1000 NCHD posts are not part of formalised training schemes [27]. Although the 2007 audit does not provide a breakdown by nationality it is widely believed $[8,27,36]$ that most of the doctors in posts of limited training value are foreign-trained doctors [10].

This paper analyses medical registration and visa data in order to examine a decade (2000-2010) of doctor migration to Ireland. Ireland's dependence on foreign-trained doctors has implications for workforce planning and presents challenges for policy makers at both an Irish and international level. This paper highlights Ireland's increasing reliance on foreign-trained doctors and questions whether active international recruitment is a suitable policy response to Ireland's failure to retain its medical workforce, particularly within the context of a global shortage of doctors. 


\section{Methods}

There is some inconsistency in the international literature in the terminology used for migrant doctors, as this term can denote nationality or country of qualification [1]. Common terms include: non-national, foreign-born, foreign-trained, overseas doctor, migrant doctor and international medical graduate [37]. The term 'foreign-trained doctor' refers to a doctor practicing in the country where they did not obtain their primary medical degree. This term does not identify medical students who have migrated in order to undertake their primary medical degree; however, it is the term used by the Organisation for Economic Cooperation and Development (OECD) and the World Health Organization (WHO). The Irish Medical Register (held by the Medical Council of Ireland) records medical school where doctors qualified, from which we identified the country of qualification. This makes the term 'foreign-trained' most appropriate for our purposes when referring to migrant doctors. The results presented in this paper will refer to doctors as a graduate of a particular country and will also categorise them as Irish graduates, non-EU graduates and EU (non-Irish) graduates. The latter are doctors who qualified in an EU country that is not Ireland.

Doctors wishing to work in Ireland must first register with the $\mathrm{MCl}$. Registration data were obtained from the $\mathrm{MCl}$ covering a ten year period 2000-2010. A request was also made to the Employment Permits Section of the Department of Jobs Enterprise and Innovation (DJEI) to obtain data on work authorisations/visas issued to doctors. The data from the $\mathrm{MCl}$ and the visa information were then compared in order to estimate the number of non-EU doctors entering Ireland on an annual basis.

\section{Registration data}

Until March 2009 the $\mathrm{MCl}$ held two Medical Registers - the General Register of Medical Practitioners and the Register of Medical Specialists. Within the General Register there were three categories of registration: full registration, internship registration and temporary registration. All non-EU qualified doctors wishing to work in Ireland initially held temporary registration and were eligible to apply for full registration after two years, but could remain on the temporary register for up to 5 years [38]. The Medical Practitioners Act 2007, which gave effect to EU directives (2005/36/EC and 2006/100/EC) came into effect in March 2009 and led to the establishment of the Register of Medical Practitioners in 2009. This register replaced the 
previous general register of medical practitioners and comprises four divisions: Trainee Specialist (comprising interns and doctors holding recognised training posts), Specialist (those who have completed specialist training), General (doctors who have not completed specialist training and do not hold a recognised training post) and Visiting EEA Practitioners (for EU/EEA citizens wishing to practice on an occasional basis) [39]. Eligibility for each division depends on stage of medical education and training and doctors can move from one division to the next [40]. The Supervised Division was added in 2011 specifically to accommodate doctors who were actively recruited from India and Pakistan [41]. Unlike the other divisions, the Supervised Division is linked to a specific post and doctors can only remain on this division of the Register for 2 years [41].

The registration databases, containing registration ID numbers but without personal information, were obtained from the $\mathrm{MCl}$ for a ten year period: 2000-2010. The registration databases record the qualifications and year of qualification of all doctors registering in that year. Following the screening and resolution of any anomalous or missing data, the databases were combined using the registration ID numbers. The total number of registrants and the number of new entrants were then determined for each year, according to country of medical school where qualified. Summary statistics and trends, in the numbers of international medical graduates registering over the ten year period, are presented. The statistical software packages SAS Version 9.2 and STATA Version 11 were used for data management and analysis. 


\section{Results}

Table 2 shows the total number of doctors registered with the $\mathrm{MCl}$ per year over a ten year period (2000-2010), which incorporates all divisions of the register both pre and post 2009. Also shown in table 2 is the number of Irish graduates and foreign-trained doctors, which comprises all doctors graduating from medical colleges outside Ireland (EU and non-EU). The table also shows foreign-trained doctors as a percentage of the total registrations at the $\mathrm{MCl}$. The final column shows the annual growth of foreign-trained doctors (\%) registering.

Table 2: $\quad$ Total registrations at the Irish Medical Council, 2000-2010

\begin{tabular}{|c|c|c|c|c|c|}
\hline Year & $\begin{array}{c}\text { Irish } \\
\text { graduates } \\
(n)\end{array}$ & $\begin{array}{c}\text { Foreign- } \\
\text { trained }(\mathrm{n})\end{array}$ & $\begin{array}{c}\text { Total number of } \\
\text { doctors } \\
\text { registered }(\mathrm{n})\end{array}$ & $\begin{array}{c}\text { Foreign-trained } \\
\text { doctors \% of all } \\
\text { registrations }\end{array}$ & $\begin{array}{c}\text { Annual growth of } \\
\text { foreign-trained } \\
\text { doctors }(\%)\end{array}$ \\
\hline 2000 & 11,298 & 1,746 & 13,044 & 13.4 & - \\
\hline 2001 & 11,838 & 2,128 & 13,966 & 15.2 & 21.9 \\
\hline 2002 & 12,210 & 2,753 & 14,963 & 18.4 & 29.4 \\
\hline 2003 & 12,393 & 3,097 & 15,490 & 20.0 & 12.5 \\
\hline 2004 & 12,415 & 3,542 & 15,957 & 22.3 & 20.2 \\
\hline 2005 & 12,595 & 4,257 & 16,852 & 25.3 & 7.1 \\
\hline 2006 & 11,662 & 4,558 & 16,220 & 28.1 & 19.2 \\
\hline 2007 & 11,638 & 5,435 & 17,073 & 31.8 & 12.4 \\
\hline 2008 & 11,793 & 6,110 & 17,903 & 34.1 & 7.5 \\
\hline 2009 & 11,491 & 6,569 & 18,060 & 36.3 & -4.5 \\
\hline 2010 & 12,457 & 6,274 & 18,731 & 33.4 & \\
\hline
\end{tabular}

The number of foreign-trained doctors registered with the $\mathrm{MCl}$ rose from 1,746 in 2000 to 6,274 in 2010 , an increase of $259 \%$ over ten years. The number of foreign-trained doctors, as a percentage of the total registrations, has also increased steadily and foreign-trained doctors now comprise a third (33.4\%) of those registered with the $\mathrm{MCl}$. The largest annual growth was seen from 2001 to 2002 and there was a decline from 2009 to 2010, when the number of foreign-trained doctors registered dropped by around 300 .

Figure 2 shows registrations categorised by Irish and EU status, using country of qualification and providing three groups: Irish graduates, non-EU graduates and EU (non-Irish) graduates. Doctors who graduated in non-EU countries make up the largest proportion of foreign-trained doctors and comprised $7.3 \%(n=957)$ of total $\mathrm{MCl}$ registrations in 2000 , rising to $25.3 \%(n=4,742)$ of registrations in 2010 . 
Figure 2: $\quad$ Total IMC registrations by country of qualification, categorised as Irish, EU (nonIrish) and non-EU graduates: 2000-2010

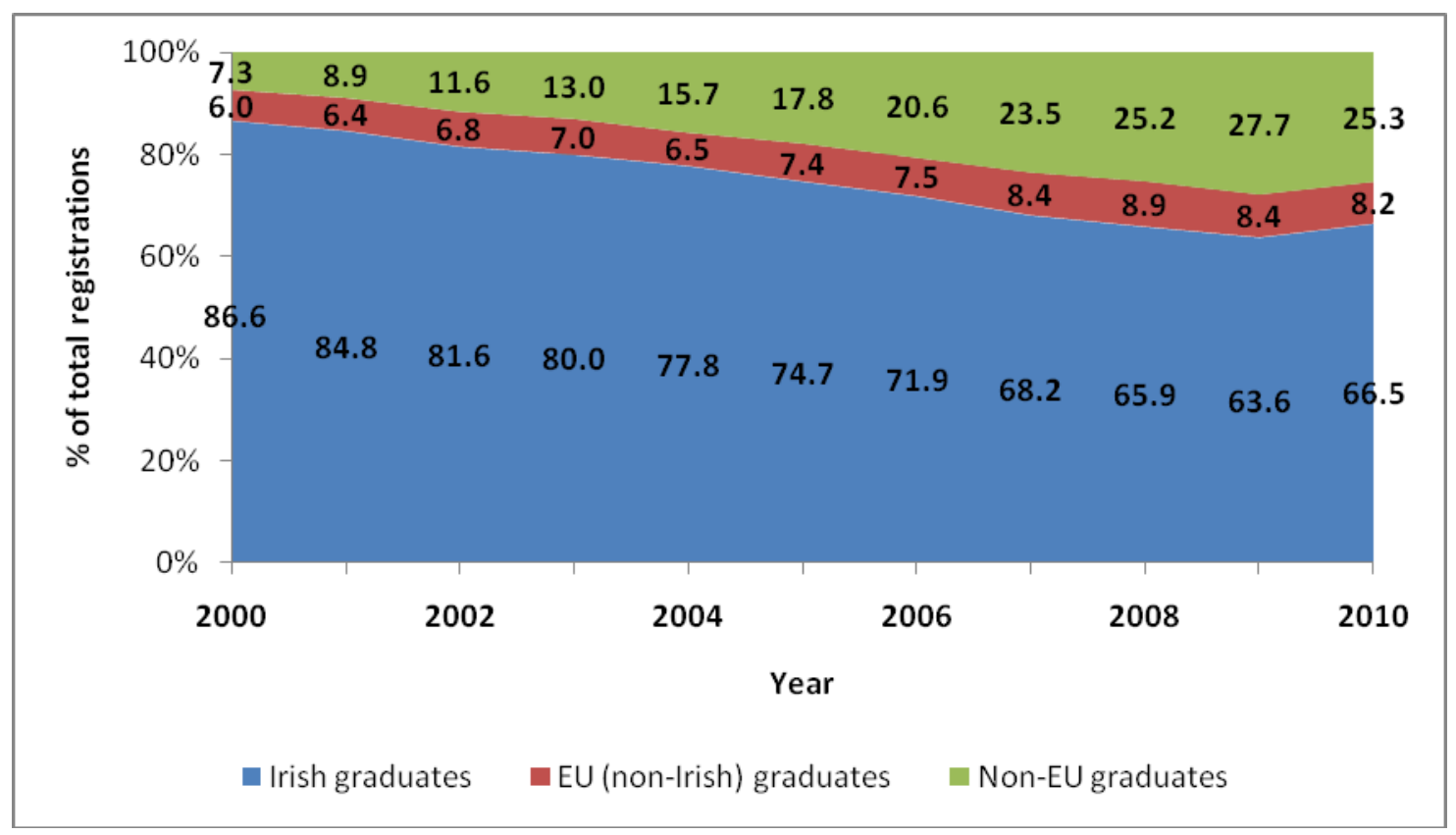

The focus of this paper is the migration of non-EU doctors to Ireland and Figure 3 shows that it is this category that has increased the most. However, trends in migration by doctors qualifying in EU countries are interesting as they reflect 'accession countries' joining the European Union in the mid 2000s [42].

Figure 3 shows that in 2000, the UK made up the largest proportion of EU (non-Irish) graduates registered with the $\mathrm{MCl}(76.7 \%, \mathrm{n}=607)$, followed by Germany $(7 \%, \mathrm{n}=55)$. By 2010, although the UK remained the largest EU source country, its share had decreased to 44\%, though the actual numbers of UK graduates increased slightly $(n=677)$. Over the decade large increases were seen in the number of EU graduates registering in Ireland from new EU countries such as Poland, Hungary and Romania. 
Figure 3: $\quad$ Country of qualification for EU graduates (excluding Ireland) 2000-2010

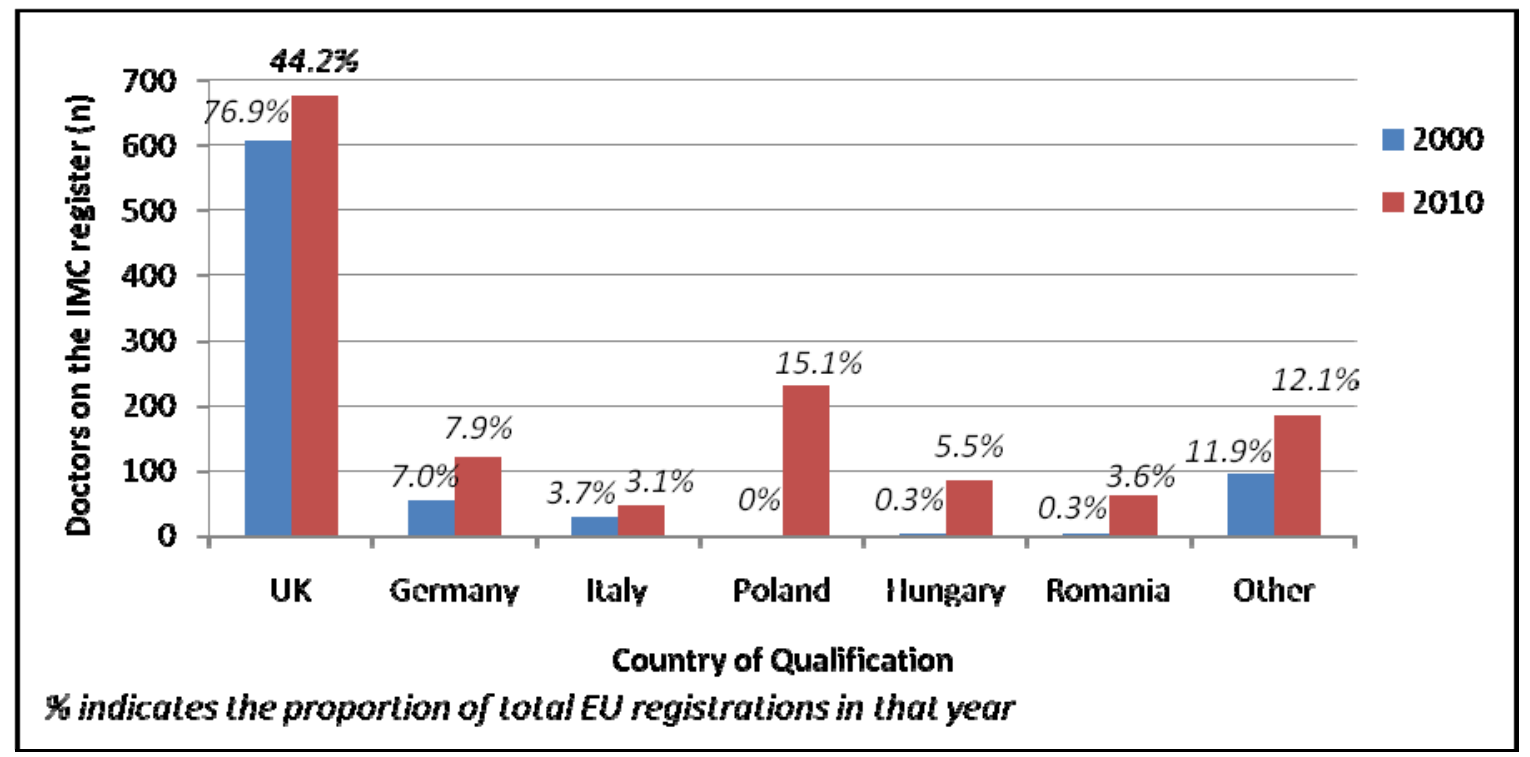

Figure 4 shows that the key source countries for non-EU graduates registering in Ireland in 2000 were: Pakistan (39.2\% of registrations), India (19.4\%), Egypt (8.3\%), Sudan (6.7\%), Australia (6.1\%) and South Africa (5.6\%). In 2010, similar source countries were recorded namely: India (9.7\%), Pakistan (22.7\%) and Sudan (8.3\%). The largest increase was for South African graduates, increasing from $5.6 \%$ in 2000 to $33.4 \%$ in 2010 . Nigeria appeared as a new source country; by $20108.2 \%$ of those registered were Nigerian graduates. 
Figure 4: Country of qualification for non-EU doctors 2000-2010

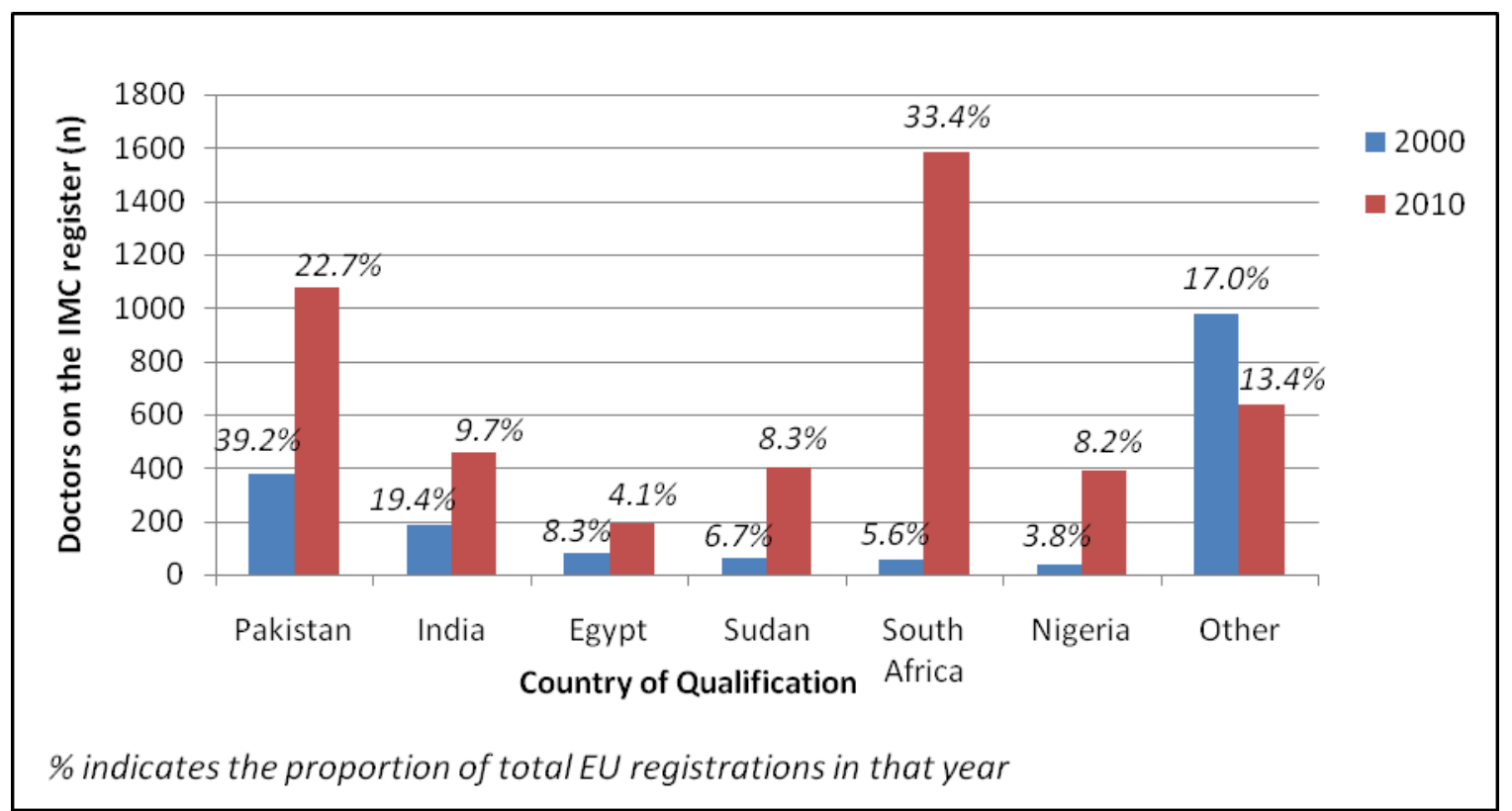

The figures above represent the total number of doctors registered in that year. It is useful to look at entrants to the $\mathrm{MCl}$ register each year as an indicator of the flow of doctors migrating to Ireland. In terms of first time entrants to the register, Figure 5 shows the gradual increase in the number of non-EU graduates over the decade. For 5 years (2005-2009 inclusive) there are more non-EU graduates than Irish graduates entering the $\mathrm{MCl}$ register. The number of non-EU graduates registering annually peaked in 2008 and decreased from 1,051 in 2009 to 586 in 2010, which coincides with Ireland's economic recession. Nurse migration to Ireland also slowed considerably during that time [43]. 
Figure 5: Number of first time entrants to the IMC register: 2001-2010

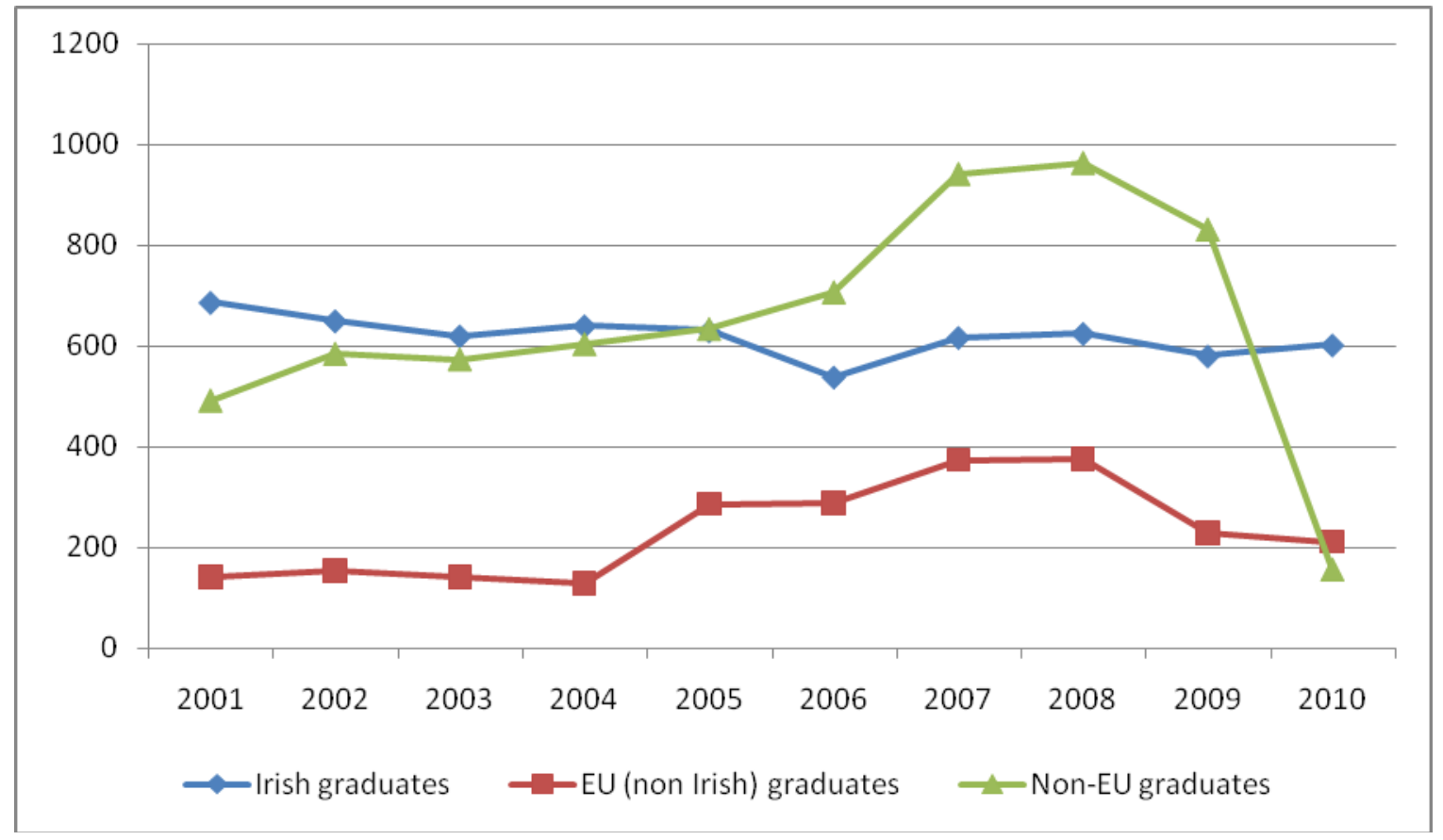

There is also an annual increase in the number of EU (non-Irish) trained graduates entering the register. The largest increases in the EU (non-Irish) category clearly relates to EU accession - the year after Poland, Hungary and Czech Republic joined the EU (in 2004) there was a corresponding twelve fold, three fold and four-fold increase in registrations respectively. Interestingly the number of EU (non-Irish) graduates entering the register peaked in 2008 and decreased thereafter, with the same trend seen for the non-EU doctors.

The number of non-EU graduates entering the $\mathrm{MCl}$ register during the period 2000-2010 was 5,998 , which exceeds the total number of non-EU graduates who were on the register at the end of $2010(n=4,742)$. This suggests that, in addition to the entry of non-EU graduates to the Medical Register, there has been a significant exit of non-EU graduates from the register during this time. Exits may be due to the doctor not currently practicing medicine in Ireland, retirement, death, or emigration.

\section{Visa data}

Data on the number of new work permits and work authorisations/work visas (hereafter referred to as working visas) issued to doctors were obtained in response to a written request to 
the Employment Permits Section of the Department of Jobs, Enterprise and Innovation (DJEI). It was anticipated that these data would closely correlate with the registration data for new entrants presented above and provide a clearer picture of the probable number of doctors who had migrated from non-EU countries in recent years, as was the case with Irish data on non-EU migrant nurses [43]. A total of 5,009 new working visas were issued to non-EU doctors in Ireland between 2002 and 2010, as shown in Figure 6.

Figure 6: Number of doctors issued with new visas to work in Ireland 2002-2010 [43]

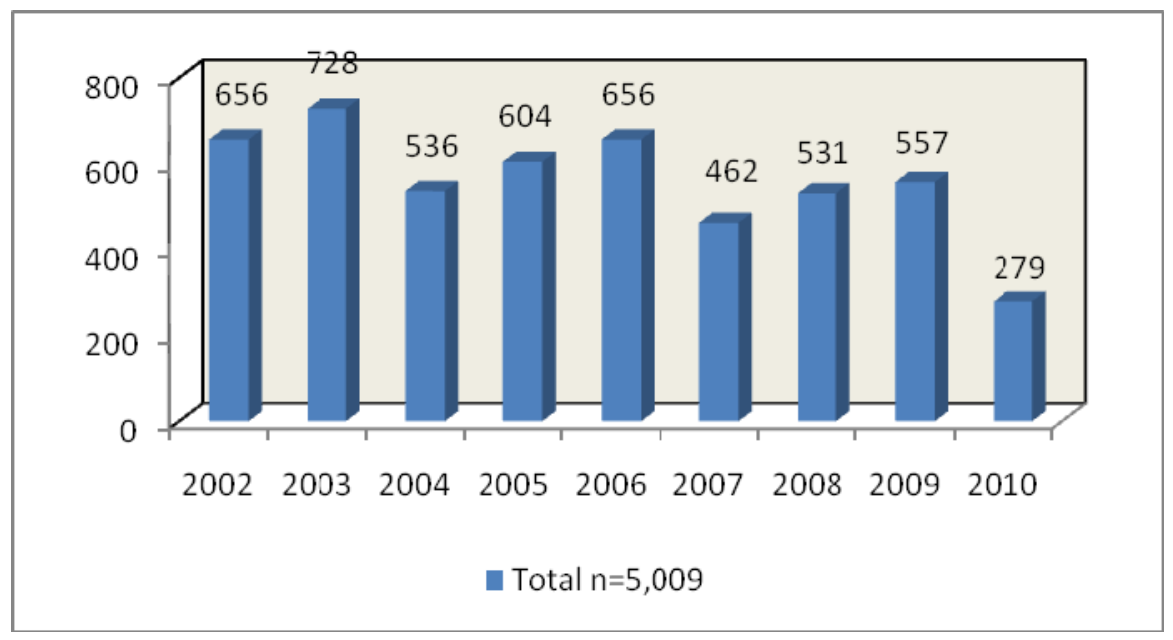

Figure 7 shows the number (n) of new visas issued to doctors of non-EU nationality and the number $(\mathrm{n})$ of new non-EU graduates entering the $\mathrm{MCl}$ register for the same period. During this period (2002-2010), a total of 5,009 visas were issued to doctors of non-EU nationality and a total of 5,998 non-EU graduates entered the $\mathrm{MCl}$ register.

For most years, the number of entrants to the register exceeds the number of new visas issued and this difference is particularly marked for 2007-2009. In 2010, both the number of new visas issued and the number of new non-EU graduates decreased sharply. The triangulation of these two sources of data supports the hypothesis that rates of migration dropped, which could have exacerbated staff shortages and could help explain why Ireland needed to actively recruit doctors from overseas in 2011. 
Figure 7: $\quad$ Number $(n)$ of new visas issued to non-EU doctors and number $(n)$ of non-EU graduates entering the IMC register during 2002-2010

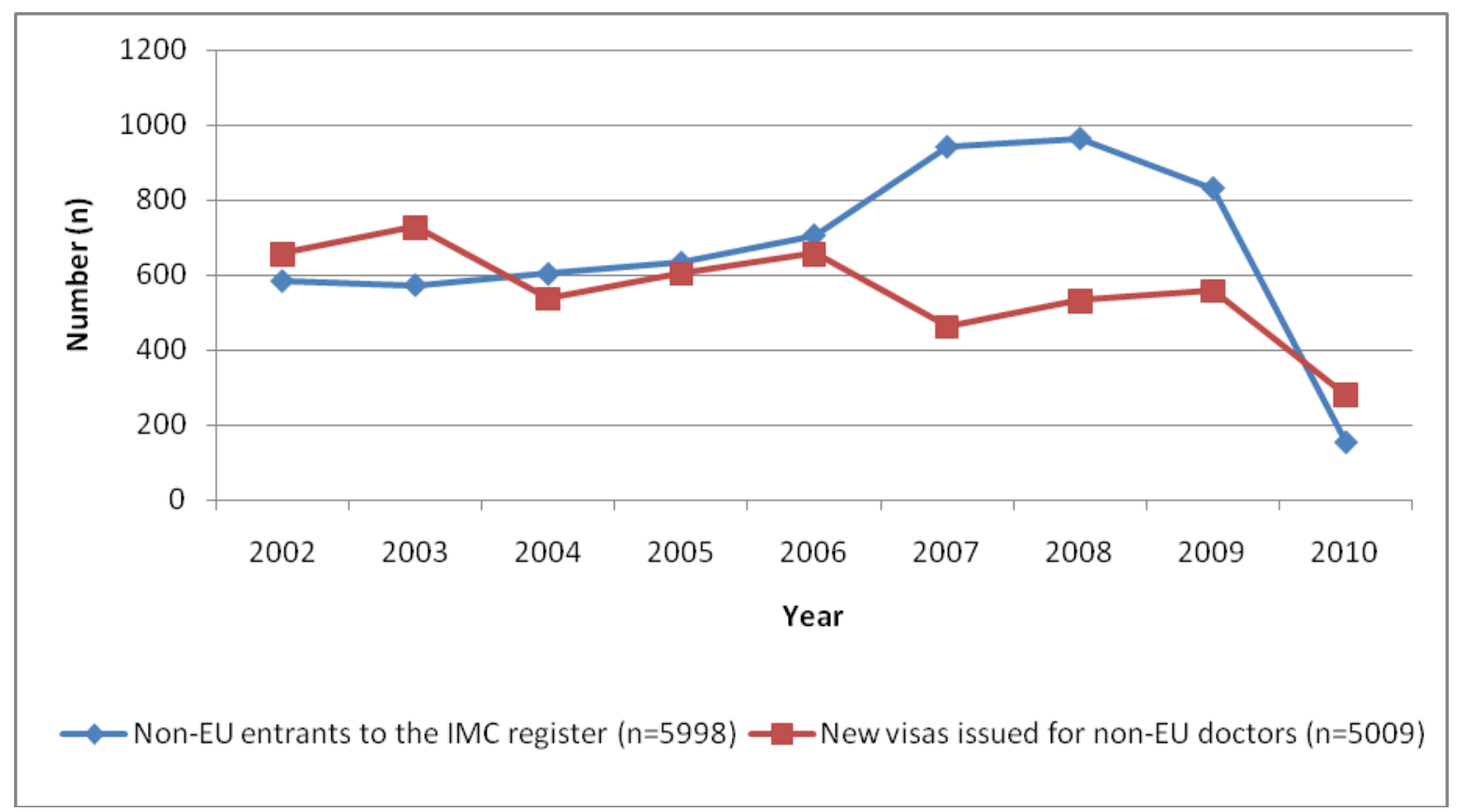

\section{Limitations of current data}

There are limitations to the data that we have presented. Neither registration nor immigration data are collated primarily for medical workforce planning purposes. However, as in other countries, these have been used here as the principal sources of migration data [44] in the absence of data that track workforce movements within and outside of the jurisdiction. This is not uncommon and it has been noted that 'no European country can provide an accurate, complete and up-to-date information on all international stocks and flows of health professionals' [1]. The principal sources of migration data include professional registers and immigration data [44]. Although each data source has limitations, it is possible by combining data sources to provide somewhat stronger evidence of doctor migration to Ireland.

Registration with the $\mathrm{MCl}$ does not mean that migration to Ireland has actually taken place, and may just indicate intent to migrate [43], or migration to Ireland with the hope of then working as a doctor in Ireland. Additionally, some doctors maintain their $\mathrm{MCl}$ registration once they have either emigrated from Ireland, or have stopped practicing medicine [9]. Furthermore, as discussed in the Irish context section, Ireland trains medical students of non-EU nationalities, who, if they register with the $\mathrm{MCl}$ after graduation, are classified as Irish graduates. Whilst it is 
believed [22] that most non-EU nationals who train in Irish medical schools leave Ireland after they have qualified, it was reported in 2010 that $19 \%$ of intern posts ( $n=99$ ) were occupied by non-EU nationals [45].

It is useful to examine the numbers of visas issued to non-EU nationals in order to get a further indication of doctor migration to Ireland. There are several reasons for the discrepancies between the registration and working visa data. The primary reason is that registration data relates to country of training, whereas the visa data records nationality. So non-EU nationals who train in Ireland would appear as 'Irish graduates' within the $\mathrm{MCl}$ data, but are likely to be categorised as non-EU nationals for immigration purposes. Also, non-EU graduates do not require a working visa if they already hold an Irish or other EU passport, are spouses of Irish or EU nationals or are asylum seekers/refugees.

The $\mathrm{MCl}$ data presented in Figure 7 relate to non-EU graduates on both the full and temporary register. The temporary register which existed prior to 2009 comprised solely of non-EU graduates and doctors on this register did not require a work permit as they were classified as postgraduate students for immigration purposes [9]. Additionally, new rules introduced in June 2010 mean that not all non-EU graduates registering with the $\mathrm{MCl}$ required work visas. Non-EU graduates taking up posts in the public sector as SHOs or Registrars, or those on the trainee specialist division (apart from interns) no longer require work permits [46].

Registration data may over estimate the number of foreign-trained doctors in Ireland, as some doctors who have registered have not moved to Ireland (an estimated $24 \%$ of South African doctors register in Ireland as a 'safety net' [30], with a view to possible future or temporary migration to undertake locum work in Ireland). Visa data may also underestimate the numbers arriving (due to visa regulations) however it is possible to reconcile the data in order to gain some understanding of migration trends. The number of visas are likely to provide the lower limit and registration data the upper limit of the numbers of doctors, implying that the true number of non-EU doctors migrating to Ireland each year will lie between the registration data and the visa data. 
Better data are needed to accurately profile doctor migration to Ireland. It is not possible to establish whether the registered doctors are actually working within the Irish health care system, or whether they are simply retaining their registration. There are diverse explanations for exits from the register and there is a need to be able to distinguish between possible reasons such as death, emigration or retirement, or any other such reasons which may arise and result in doctors leaving the register on a temporary or permanent basis. Furthermore, it is not possible to distinguish between permanent and temporary migrants. In order to incorporate doctor migration into overall health workforce planning it is essential to have data on the stock of migrant workers within the country and the flow of workers out of the country [1]. Currently Ireland does not have this information available. 


\section{Discussion}

The results presented in this paper, using Ireland as a case study, illustrate three important issues for destination countries heavily reliant on foreign-trained doctors: 1 ) the need for better data systems to monitor migration flows within and across national borders, 2) the health workforce planning implications for destination countries of large scale reliance on recruitment of foreign-trained doctors and 3) ability to comply with the WHO Global Code on the International Recruitment of Health Personnel.

\section{Migratory flow data systems}

Although there are limitations to the data presented here, registration and immigration data are the best and indeed the only data currently available to monitor migration in the Irish context. The data show that key source countries have changed, shifting from the UK at the beginning of the decade to Pakistan, India, Sudan, Nigeria and South Africa by 2010 . There had been concern about the out-flow of doctors from accession states following the expansion of the EU [42] and data presented here shows that this did indeed stimulate a flow of doctors from Eastern Europe, particularly from Poland, to Ireland. The increased numbers of doctors from Sudan and Nigeria, both countries facing critical shortages of doctors [3], raise ethical issues as the loss of doctors through migration may impede the ability of source countries to provide health care. Furthermore, as the total number of non-EU graduates in 2010 is smaller than the number of entrants for the ten year period, it suggest a net migration of doctors out of Ireland, illustrating the fluid nature of health worker migration.

What is evident from the data presented here is that much better information is needed about the flow of foreign and Irish trained doctors into and out of the Irish health system than is currently available. It is important to know the locations, specialties and grades of foreign (and domestically) trained doctors working in the Irish health system, and their career intentions. It has been widely acknowledged that many non-EU doctors in Ireland are working in posts of limited training value [47] and policies need to be developed in order to manage the migration process so that it does not create a win-lose situation [1]. The 2011 active international campaign in Pakistan and India was conducted in response to critical shortages and it is not known how these doctors will fit into the overall workforce plan once their 2-year contracts are 
finished. They may be retained within the Irish health system, return home, or migrate onwards to alternative destination countries, however it is not yet possible to determine this.

\section{Migration trends and their implications for workforce planning in Ireland}

Ireland needs to have comprehensive data on migratory flows. The limited data mean that policy makers are currently unable to make informed decisions about levels of doctor migration and the reciprocal implications of these flows for the domestic production and training pipeline of doctors [42].

It is essential to have an understanding of both inward and outward flows of health professionals in order to incorporate this information into the workforce planning process [1]. Ireland's NCHD shortage has been widely reported [18] and gaps between supply and demand make it increasingly difficult for policy makers to predict future trends in relation to needs [48]. Recent Irish health workforce planning strategy documents [49] recognise the need for better workforce planning for ensuring the delivery of health service goals and the lack of comprehensive data on 'migratory flows' remains a core issue.

The large increase in the numbers of foreign-trained doctors registering at the $\mathrm{MCl}$ supports the hypothesis that Ireland is becoming increasingly dependent on foreign-trained doctors to make up the short-fall of Irish trained doctors. Although anecdotal evidence suggests that Irish trained doctors are leaving $[50,51]$ the available data sources (medical registration and visa data) fail to capture this emigration. A difficulty in capturing / recording health worker emigration is a problem shared by many source countries $[1,37]$. The data presented here suggest that that increases in the numbers of foreign-trained doctors have been largely the result of passive recruitment rather than as a result of active international recruitment campaigns; and after 2008 there was a dramatic (four-fold) fall in the number of non-EU doctors entering the register, and a corresponding decrease in the total numbers registered. Emigration can be a major cause of attrition from the stock of doctors within a country [37]. If Ireland is training but not retaining doctors the resulting reliance on foreign-trained doctors to make up the shortfall suggests inadequate health workforce planning. Additionally, it is not known to what extent Ireland is able to retain foreign-trained doctors. It is estimated that $60 \%$ of NCHDs emigrate in order to secure consultant employment [27] and foreign-trained doctors in 
particular feel disadvantaged with regards to access to consultant posts in Ireland [10], with one non-EU doctor putting it "'I don't think I have any career prospects - that is why we are planning to move'" [52].

Such a reactive approach to workforce planning raises issues of sustainability and ability to compete in a global market [53] especially in the current economic climate. A recent OECD/WHO policy brief suggests that the recent economic crisis will not drastically affect international migration of health professionals and states that 'employment in the health sector is more resilient to a cyclical downturn than employment in other sectors and demand for healthcare is certainly not decreasing in the short term due to the crisis' [4]. However, while this might be true globally, in Ireland, the decreased salaries [27] brought about by the economic downturn, as well as changes in NCHD contracts [10] and new registration procedures [40] make it a less attractive destination for foreign-trained doctors. A decrease in non-EU graduates joining the register after 2008 suggests that Ireland is a less attractive destination for foreigntrained doctors, a factor perhaps reflected in the need (from 2011) for active recruitment campaigns to fill NCHD vacancies.

\section{Ireland's responsibilities as part of the Global Code}

Major destination countries such as Ireland were required under the WHO Global Code of Practice to report to the WHO and the World Health Assembly in 2012 on the inflows of foreigntrained doctors and nurses. In accordance to Article 7.1 Member states will be encourage to provide information to the Secretariat on health personnel migration [54]. Ireland is in danger of failing to comply with the Code, both through being unable to retain workers and subsequently reacting by filling shortages through active international recruitment. More substantive responsibilities under the Code are the member states are encouraged to 'train and retain' a sustainable health workforce and are discouraged from actively recruiting health professionals from developing countries who face critical shortages of health workers [7].

The 2011 active international campaign to recruit junior doctors from India and Pakistan resulted in the recruitment of 230 doctors [41]. These are not countries normally considered as countries experiencing severe shortages; however, the absence of negative effects on sending countries' health systems should not be assumed in that critical specialised staff can be lost 
through active recruitment campaigns. Assessments of possible effects can be considered a responsibility on destination countries under the Global Code. It is clear that improved data is the first step towards understanding health worker migration as well as being important for reporting to the WHO.

\section{Conclusion}

This paper highlights the difficulties that are faced when trying to monitor doctor migration and assess its impact on the workforce. There is a global need to produce a sufficient stock of doctors to meet demand and Ireland needs to develop ethical, effective and sustainable health workforce policies in order to ensure that its health services are adequately staffed. Ireland's dependence on foreign-trained doctors indicates an inability to train and retain sufficient doctors to meet demand and suggests the need for a strengthened health workforce planning system. This will require Ireland to develop and maintain a comprehensive record of inflows to the health workforce, including migratory flows. Furthermore there needs to be more detailed information about foreign-trained doctors currently in the health workforce, in terms of how they were recruited, what stage in their career they were on arrival, where they practice in Ireland and their levels of satisfaction with working conditions. Information about the motivations, aspirations and career plans of foreign-trained doctors will aid policy makers and planners understand their future plans and will allow the Irish government to retain and better utilise them, once they are working within the Irish health system.

In the short to medium term, the key question is whether Ireland will be able to continue to attract and retain foreign-trained doctors, without contributing to undermining the health systems in the source countries from which these doctors come. Of critical and long-term importance is the need for Ireland to identify the reasons for its failure to retain the doctors it trains and implement retention measures so as to remove its dependence on foreign-trained doctors. Such reliance on foreign-trained doctors is precarious in the context of a recession and a worldwide shortage of doctors which will create increased global competition for this valuable and scarce resource. 


\section{Acknowledgements}

The Medical Council of Ireland provided the anonymised medical registration data and the Employment Permits Section of the Department of Jobs, Enterprise and Innovation provided the visa data used in the analysis. Neither organisation is responsible for any of the views or interpretation in the paper. The Doctor Migration Project is funded by the Irish Health Research Board under the research grant HRA HSR/2010/18. 


\section{References}

[1] Buchan J. How can the migration of health service professionals be managed so as to reduce any negative effects on supply? In: Permanand G, editor. WHO European Conference on Health Systems. Estonia: WHO Regional Office for Europe and European Observatory on Health Systems and Policies, 2008.

[2] Mejia A. Migration of Physicians and Nurses: a World Wide Picture. International Journal of Epidemiology 1978; 7:207-15.

[3] WHO. The World Health Report - Working Together For Health. Geneva: World Health Organisation, 2006.

[4] OECD. International Migration of Healthworkers: Improving International Co-operation To Address The Global Health Workforce Crisis. Organisation for Economic Co-operation and Development (OECD), 2010.

[5] Wismar M, Maier C, Glinos I, Dussault G, Figueras J. Health Professional Mobility and Health Systems Evidence from 17 European countries. United Kingdom: World Health Organisation on behalf of the European Observatory on Health Systems and Policies, 2011.

[6] Stilwell B, Diallo K, Zurn P, Vujicic M, Adams O, Dal Poz M. Migration of health care workers from developing countries: strategic approaches to its management Bulletin of the World Health Organisation 2004; 82:595-600.

[7] WHO. The WHO Global Code of Practice on the International Recruitment of Health Personnel. Geneva: The World Health Organisation, 2010.

[8] MCl. Comhairle na nDochtúirí Leighis Medical Council Report 1994-1999. Dublin: Medical Council of Ireland (MCl), 1999.

[9] Quinn E. Managed Migration And The Labour Market - The Health Sector in Ireland. Ireland: European Migration Network, 2008:1-40.

[10] Wójcicka A, Bobek A, Salamonska J. National report: Ireland. Warsaw, Poland: Mobility of Health Professionals (MoHProf), 2009:1-140.

[11] Hussey P. International migration patterns of physicians to the United States: A cross-national panel analysis. Health Policy 2007; 84:298-307.

[12] Hagopian A, Thompson MJ, Fordyce M. The migration of physicians from sub-Saharan Africa to the United States of America: measures of the African brain drain. Human Resources for Health 2004; 2:17-26.

[13] Chen L, Boufford JI. Fatal Flows - Doctors on the Move. The New England Journal of Medicine 2005; 353:1850-2.

[14] FÁS. Healthcare Skills Monitoring Report. Dublin: FÁs, 2005.

[15] DOHC. Report of the National Task Force on Medical Staffing: The Hanly Report. Dublin: Department of Health and Children (DOHC), 2003.

[16] FÁS. National Skills Bulletin 2009. . A study by the skills and labour market research unit (SLMRU) in FÁS for the expert group on future skills needs. Dublin: FÁs, 2009.

[17] DOHC. Opening Address by the Minister for Health to the Joint Committee on Health and Children. Dublin: Department of Health and Children (DOHC) 2011:(http://www.dohc.ie/press/speeches/2011/20111006a.html).

[18] HSE. February 2011 Performance Report on NSP 2011. Dublin: Health Services Executive (HSE), 2011.

[19] Thomas S, Layte R. General Practitioner Care. In: Layte R, Barry M, Bennett K, Brick A, Morgenoth E, Normand C, O'Reilly J, Thomas S, editors. Projecting the Impact of Demographic Change on the Demand for and Delivery of Healthcare in Ireland. Dublin: The Economic and Social Research Institute (ESRI), 2009. 
[20] DOHC. Medical Education in Ireland: A New Direction. Report of the Working Group on Undergraduate Medical Education and Training - The Fottrell Report. Dublin: Department of Health and Children (DOHC), 2006.

[21] Hawthorne L, Hamilton J. International medical students and migration: the missing dimension in Australian workforce planning? Medical Journal of Australia 2010; 193:262-5.

[22] DOHC. Preparing Ireland's doctors to meet the Health Needs of the 21st Century. Report of the Working Group on Undergraduate Medical Education and Training (the "Buttimer Report"). Dublin: Department of Health and Children (DOHC), 2006.

[23] MCl. A Review of Medical Schools in Ireland. Dublin: Medical Council of Ireland (MCI), 2007.

[24] HSE. Annual Assessment of NCHD Posts July 2011 to June 2012. Dublin: Health Services Executive (HSE) - Medical Education and Training Unit, 2011.

[25] Garcia-Perez M, Amaya C, Otero M. Physicians' migration in Europe: an overview of the current situation. BMC Health Services Research 2007; 7.

[26] IMO. Benchmark NCHD Survey 2011. Dublin: Irish Medical Organisation (IMO), 2011.

[27] IMO. Submission to the Oireachtas Joint Committee on Health and Children - Non Consultant Hospital Doctors. Dublin: Irish Medical Organisation (IMO), 2011.

[28] McIntosh T, Torgerson R, Klassen N. The Ethical Recruitment of Internationally Educated Health Professionals: Lessons from Abroad and Options for Canada. Ontario: Canadian Policy Research Networks, 2007.

[29] DOHC. Martin takes medical recruitment to India and Pakistan. Dublin: Department of Health and Children (DOHC), 2000:(http://www.dohc.ie/press/releases/2000/20000918a.html).

[30] Bidwell P, Thomas S. The dynamics of temporary medical migration: A case study of South African doctors working in Ireland. The Irish Forum for Global Health 2012 'The Global Health Workforce: Pathways to Health' Why are health workers important? Dublin, 2012.

[31] MCl. 5th Medical Council: A report on the 5-year term 1999-2004. Dublin: Medical Council of Ireland $(\mathrm{MCl}), 2004$.

[32] OECD. Health at a Glance: Europe 2010. Organisation for Economic Cooperation and Development (OECD), 2010.

[33] DOHC. Address by the Minister for Health Dr. James Reilly T.D. to the Select Committee on Health Estimate for 2011. Dublin: Department of Health and Children (DOHC), 2011:(http://www.dohc.ie/press/speeches/2011/20110719.html).

[34] FÁS. A Quantitative Tool for Workforce Planning in Healthcare: Example Simulations. Dublin: FÁs \& Expert Group on Future Skills Needs, 2009.

[35] PGMDB. Survey of NCHD Staffing at 1 October 2008. Postgraduate Medical and Dental Board, 2008.

[36] HSE. National Audit of SHO and Registrar Posts. Dublin: Health Executive Board (HSE), 2007.

[37] Dussault G, Fronteira I, Cabral J. Migration of health personnel in the WHO European Region. Lisbon: Instituto de Higiene e Medicina Tropical, 2009.

[38] elSB. The Medical Practitioners Act 1978. Irish Statute Book. Dublin: Office of the Attorney General, 1978.

[39] elSB. Medical Practitioners Act, 2007. Irish Statue Book. Dublin: Office of the Attorney General, 2007.

[40] $\mathrm{MCl}$. A guide to the application procedure and registration rules for registration in the Register of Medical Practitioners in the: Trainee Specialist Division, Specialist Division and the General Division. Dublin: Medical Council of Ireland (MCI), 2011.

[41] MCI. Medical Council enewsletter - Autumn Edition, 2011. Dublin: Medical Council of Ireland (MCl), 2011.

[42] Buchan J, Perfilieva G. Health Worker Migration in the European Region: Country Case Studies and Policy Implications. Copenhagen: WHO Regional Office for Europe, 2006.

[43] Humphries N, Brugha R, McGee H. Overseas Nurse Recruitment: Ireland as an illustration of the dynamic nature of nurse migration. Health Policy 2008; 87:264-72. 
[44] Stilwell B, Diallo K, Zurn P, Dal Poz M, Adams O, Buchan J. Developing evidence based ethical policies on the migration of health workers: conceptual and practical challenges. Human Resources for Health 2003; 1.

[45] HSE. Interim Report on the implementation of recommendations of the National Committee report on the intern year. Phase 1: May 2009-July 2010. Dublin: Health Services Executive (HSE) Intern Implementation Group, 2010.

[46] DJEl. Employment Permits for Nurses and Doctors 2011. Department of Jobs Enterprise and Innovation (DJEI), 2011:(http://www.djei.ie/labour/workpermits/doctorsandnurses.htm).

[47] Birchard K. Ireland's doctors tackle institutional racism. The Lancet 2001; 357:1348.

[48] Simoens S, Hurst J. The Supply of Physician Services in OECD Countries. OECD Health Working Papers No 21. Paris: OECD, 2006.

[49] HSE, DOHC. An Integrated Workforce Planning Strategy for the Health Services 2009-2012. Dublin: Health Service Executive (HSE) and Department of Health and Children (DOHC), 2009.

[50] Gantly D. Retention not recruitment is key problem. Irish Medical Times. Dublin, 2012:http://www.imt.ie/news/latest-news/2012/04/retention-not-recruitment-is-key-problem.html.

[51] O'Connor A. Will the last doctor to leave Ireland please turn the lights off. Medical Independent. Dublin,

2010:http://www.medicalindependent.ie/page.aspx?title=will the last doctor to leave ireland please turn the lights off.

[52] Humphries N, Bidwell P, Tyrell E, Brugha R, Thomas S, Normand C. 'I am kind of in Stalemate'. The Experiences of Non-EU Migrant doctors in Ireland. In: Buchan J, Wismar M, Glinos IA, editors. Volume II: Health professional mobility and health systems Evidence from 17 European countries, forthcoming.

[53] Zurn P, Dumont J-C. Health Workforce and International Migration: Can New Zealand Compete? OECD Health Working Paper No 33. Paris, France: OECD, 2008.

[54] WHO. WHO Global Code of Practice on the International Recruitment of Health Professionals. Draft guidelines on monitoring the implementation of the WHO Global Code. Geneva: The World Health Organisation, 2011. 